\title{
Efficacy of Intermittent Compression Therapy versus Kinesio Tape on Cellulite in Females
}

\author{
AMIRA A. NEWAGY, M.Sc.*; HALA M. HANAFY, Ph.D.*; MARWA A. RAHMAN, Ph.D.* and \\ ROKIA A. SOLIMAN, M.D.** \\ The Department of Physical Therapy for Women Health, Faculty of Physical Therapy, Cairo University* and \\ The Department of Biological Anthropology, National Research Centre**
}

\begin{abstract}
Background: Cellulite is defined as changes in the surface contour of the skin that result in orange peel or "mattress" appearance of the skin. Cellulite is not defined as a pathologic condition, but is a substantial cosmetic concern for many adult females.

Aim of Study: To evaluate the efficacy of intermittent compression therapy versus Kinesio tape on cellulite in females.

Subjects and Methods: They were selected from students of Faculty of Physical Therapy Cairo University since October till end of December 2018, thirty females with femoral adipose tissue cellulite grade $\geq 1$ according to Nurnberger-Muller scale at their thighs. Their ages ranged from 19-25 years and their body mass indices did not exceed $35 \mathrm{~kg} / \mathrm{m}^{2}$. They were divided randomly into two groups, Group (A) (kineso tape group): Was consisted of 15 females; they all received kinesio tape for 6 weeks in addition to low caloric diet (1200kcal/day) and condition related advices. Group (B) (intermittent compression therapy group): Was consisted of 15 females, they received intermittent compression therapy for 6 weeks in addition to low caloric diet $(1200 \mathrm{kcal} /$ day $)$ and condition related advices as in group (A) inclusion criteria thirty females suffering from grade $\geq 1$ cellulite according to Nurnberger-Muller scale with femoral adipose tissue, their ages ranged from 19-25 years, their body mass indices did not exceed $35 \mathrm{~kg} / \mathrm{m}^{2}$. Exclusion criteria history of uncontrolled hypertension, malignancy, mental disorders, diseases of skin (dermatological diseases), inflammation within treatment area and history of Deep Venous Thrombosis (DVT).
\end{abstract}

Results: The percent decrease in the mean value of ultrasound in both groups (A \& B) were $4.81 \%$ and $14.36 \%$ respectively, the percent decrease in the mean value of round tape measurement in both groups A and B were $2.39 \%$ and $3.64 \%$ respectively and there was statistical significant decrease in the median value of photonumeric cellulite severity scale in group B [8.0 (4.50-11.)] when compared with its corres ponding value in group A [9.5 (6.0-12.0)] with Z-value $=-2.124$ and $p$-value $=0.034$.

Correspondence to: Dr. Amira A. Newagy, The Department of Physical Therapy for Women Health, Faculty of Physical Therapy, Cairo University
Conclusion: The results of this study showed that the use of KT and intermittent compression therapy resulted in significant reduction in femoral adipose tissue cellulite were observed favouring intermittent compression therapy approach.

Key Words: Cellulite - Intermittent compression therapy Kinesio tape.

\section{Introduction}

CELLULITE is a condition in which localized metabolic failure in the fatty layer affects the body skin surface and occurs mainly in female. The condition usually manifests itself as a bumpy or nodular surface contour of the skin in such areas as the waist, thighs, and abdomen in female [1]

Cellulite is a widespread phenomenon that gives the skin an orange-peel appearance which is particularly found on the thighs and buttocks of postadolescent women, it is also present even in most of the fit women [2].

The term "cellulite" was first used in the 1920s to describe an aesthetic alteration of the cutaneous surface. Since then, other more descriptive names have been suggested; these include nodular liposclerosis, odemato-fibrosclerotic panniculopathy, panniculosis, Gynoid Lipodystrophy (GLD) and others. Etymologically, cellulite is defined as a localized metabolic disorder of the subcutaneous tissue which provokes an alteration in the female body shape [3]

Cellulite is a cosmetic problem and is of increasing concern of female with its "orange-peel" or "cottage cheese" appearance affecting at least $85 \%$ of female. It is not specific for overweight female. It is a complex problem involving the micro circulatory system and lymphatic, the extra cellular matrix and the presence of excess subcu- 
taneous fat that bulges into dermis. It occurs mainly on the lower limbs, pelvic region (gluteal femoral regions) and abdomen and is characterized by an orange peel [4].

Cellulite is prevalent in female of all races. It is more common in white than black females. It appears to be strong hormonal component as it is rarely seen in males [5]. Cellulite affects $90 \%$ of the female between the ages 30-55 years old whether they are slim, fat, or obese [6]

Cellulite is characterized by irregular relief alterations in the appearance of the skin surface which acquires an orange peel, cottage cheese or mattress aspect. It is unsightly dimpling frequently found on hips, thighs, buttocks, and even on the abdomen of female, especially after puberty, which progresses with age $[\mathbf{7 , 8 ]}$

Cellulite is considered a non inflammatory disorder of the subcutaneous tissue, giving the skin an orange peel, cottage cheese or mattress appearance [7].

This condition affects most commonly the thighs, lower legs, arms and abdomen Cellulite develops in four stages. Which are Stage 0 the surface of the skin remains smooth; however, a slight "orange-peel" effect becomes visible when the skin is pinched gently between forefinger and a thumb, Stage I there is a slight fibrosis of the subcutaneous tissue and when the pinch test is applied, a lumpiness or unevenness of the skin surface can be noticed. The surface effects are minimal, yet the" orange peel" look of the skin can easily be detected, Stage II the symptoms exacerbate, there is a significant subcutaneous fibrosis and small nodules are palpable under the skin surface. The skin appears tethered and puckered without pinching; Stage III final stage is marked by hard palpable nodules of collagen in the dermal region, which may press on nerve fibres and capillaries, causing pain. The surface displays considerable unevenness, and can easily bruise when pressed or pinched [9].

Cellulite is a disorder of the subcutaneous layer that adversely changes the appearance of the overlying superficial skin. Changes in the fibrotic septae between fat cells and tissue reduce the metabolic rate, thus congestion the tissue repercuting on the skin's external aspect. Skin roughness alteration translates to bumpy, uneven skin [10].

The dermato-functional physiotherapy falls in the evaluation process of the Gynoid Lipodystrophy (GL) and may use the assessment protocol for gynoid lipodystrophy developed in Brazil. Validated by some authors, [11]. Which is a tool for collecting personal information, physical, morphological and functional. In addition, physical therapy works in prevention as well as treatment of Gynoid Lipodystrophy (GL), with the goal of improving local circulation and reduces fibrosis, through features such as manual lymphatic drainage, endermologie, ultrasound, iontophoresis, electrolipoforese, pressure therapy, among others [3,12]

Functional elastic bandages have been used in the treatment of circulatory and skin changes, such as oedema and scarring [13,14]

The Kinesio Taping (KT) is a technique of applying elastic bandages, which has been used on a large scale. Theoretically, the bandage was developed to adapt optimally to the human skin, and according to the adopted voltage, generate various benefits which are explained in a general way by stimulation of skin receptors $[15,16]$

Although it is a widely used technique at present, there is little scientific evidence about its possible effects and, moreover, the existing results are controversial. Greater still is the lack of scientific research on the effect of KT in dermatofunctional pathologies, especially with regard to Gynoid Lipodystrophy (Gl) [17]

Some studies bring good results regarding the use of Kinesio Tape (KT) to reduce oedema, without tension applied and in form of a "web", by directing the banding towards the lymphatic return $[18,19]$

Compression therapy is a conservative therapy that aims to reduce the volume of interstitial fluid by promoting venous and lymphatic drainage. It tackles oedema by reducing fluid and preventing build up, but it does not reduce fatty tissue [20]

\section{Purpose of the study:}

The aim of this study is to compare between the effect of using kinesio tape and intermittent compression therapy on cellulite in females.

\section{Subjects, Material and Methods}

\section{I- Subjects:}

This study was carried out on thirty females with femoral adipose tissue cellulite grade > 1 according to Nurnberger-Muller scale at their thighs. They were selected from students of Faculty of Physical Therapy Cairo University. Their ages ranged from 19-25 years and their body mass indices did not exceed $35 \mathrm{~kg} / \mathrm{m}^{2}$. They were divided 
randomly by using flip coin into two groups equal in number, Group (A) (kinesio tape group) and Group (B) (intermittent compression therapy group).

Group (A) (kineso tape group): Was consisted of 15 females; they all received kinesio tape for 6 weeks in addition to low caloric diet (1200kcal/day) and condition related advices.

Group (B) (intermittent compression therapy group): Was consisted of 15 females, they received intermittent compression therapy for 6 weeks in addition to low caloric diet (1200kcal/day) and condition related advices as in group $\mathrm{A}$.

All participants were given a full explanation of the assessment and treatment procedures and then they signed a consent form before participating in this study (Appendix I).

\section{Criteria of patient selection:}

Females in both groups were chosen under the following criteria:

\section{Inclusion criteria:}

1- Thirty females suffering from grade $>$. 1 cellulite according to Nurnberger-Muller scale with femoral adipose tissue.

2- Their ages ranged from 19-25 years.

3- Their body mass indecis did not exceed $35 \mathrm{~kg} / \mathrm{m}^{2}$

\section{Exclusion criteria:}

Any participant was excluded if she meets one or more of the following criteria: History of uncontrolled hypertension, malignancy, mental disorders, diseases of skin (dermatological diseases), inflammation within treatment area and history of Deep Venous Thrombosis (DVT).

\section{II- Equipment:}

A-Assessment equipment:

1- Weight height scale: Was used to measure weight and height to calculate BMI for each female before enrolment in this study.

2- Nurnberger-Muller scale: Was used to assess the grade of cellulite for each female before enrolment of this study for both groups [21].

3- Ultrasonography: High frequency ultrasonography allowed the evaluation of epidermal and dermis thickness, as well as the morphology of the upper layer of the subcutaneous tissue and dermis. The classical ultrasonography enabled taking objective measurements of the thickness of subcutaneous tissue [22]
4- Round tape measurement: All circumferences were measured in standardized conditions at the mid of the thigh below greater trochanter by $20 \mathrm{~cm}$ of each female before starting the study and after the treatment course.

5-Photography (visual evaluation): Graphic image was taken before and after the treatment course for both groups and evaluated by using photo numeric cellulite severity scale (Appendix III). The new classification of cellulite as mild, moderate, and severe is determined by the severity scores obtained for section $A$ to $E$, as illustrated below: Classification of cellulite according to the obtained photoneumeric cellulite severity scale scores: Mild (1-5) moderate (6-10) severe (11-15) [7]

\section{B- Treatment equipment:}

I- Kinesio tape (Tiger K Tape): Was conducted for group (A).

$100 \%$ cotton, $3 \%$ spandex, $10 \%$ polymer and $15 \%$ ethyl acetate, made in Korea, latex free, 170$180 \%$ stretch, hypoallergenic, water resistant, allows the skin to breathe, ultra flexible and mouldable to the body's contours, thickness and weight of the tape is similar to that of human skin, easily tolerated with very few contraindication, allows the natural joint and muscle ROM and does not restrict motion, elastic properties to help support and reduce muscle fatigue, helps assist the flow of lymphatic drainage, can be worn for 3-5 days without reapplication.

II- Intermittent compression therapy: Doctor life, model: DL2002B (Basic), weight: 2.5, dimension: 195 (w) X 250 (D) X 210 (h) mm, power consumption: 50VA, power source: V 220Vac, 50/60Hz $110 \mathrm{Vac}, 50 / 60 \mathrm{~Hz}$, time adjustment: 0-30 minutes, made in korea, was conducted for group (B).

\section{III-Procedures:}

A-Assessment procedure:

- A full history was taken from each female in both groups before starting the study to exclude ineligible cases.

- The body weight and height were measured for each female before starting the study. Weightheight scale was calibrated. Then BMI was calculated by dividing the weight in kilograms by the square of the height in meters:

$$
\mathrm{BMI}=\begin{gathered}
\text { Weight } \\
\text { Height square }(\mathrm{kg} / \mathrm{m} 2)
\end{gathered}
$$


- All females with BMI $<35 \mathrm{~kg} / \mathrm{m}^{2}$ were enrolled in this study.

- The grade of cellulite for each female was determined by using numberger-muller scale, as the following:

Grade (0): No dimpling when the subject is standing and lying. The pinch test reveals "folds and furrows" but there is no mattress-like appearance.

Grade (1): No dimpling while the subject is standing or lying, but the pinch test reveals the mattress like appearance.

Grade (2): Dimpling appears spontaneously when standing and not in lying down.

Grade (3): Dimpling is spontaneously positive standing and lying down.

Each female met a grade $>1$ on this scale was enrolled in this study after that all female in both groups were evaluated by using the following before and after the treatment.

1- Ultrasonography: Ultrasonography device: Intelligent ultrasonic cure instrument.

It was used to measure the thickness of subcutaneous tissue below skin of the back of the thigh for each female before starting the study and after the treatment course.

- Frequency: 3.5-5MHz.

- Intensity: $10 / \mathrm{cm}^{2}$.

- Voltage: AC 220-240v.

- Power: $10 \mathrm{w}$.

- It consists of two probes.

- Made in USA, 2011.

\section{2-Round tape measurement:}

- Was used to measures thigh circumference for each female in both groups.

- Female was instructed to stand up in relaxed state with her hands away from her body and thighs were cleared of the clothes.

- The level of measurement would be recognized by $20 \mathrm{~cm}$ below greater trochanter.

- Round tape measurement was rounded around the thigh at the recognized level in the area of cellulite. The number appeared at the point of round tape crossing, indicated the round measurement for female.

- These measurements were performed before starting the study and after the treatment course.

\section{3-Photoneumeric cellulite severity scale: (Photog-} raphy):

- Females were instructed to stand up in relaxed state with her hands away from her boy and thighs were cleared of the clothes.

- By using a camera, a photo was taken to the area of cellulite for evaluation.

- The taken photo was examined and evaluated by comparing it with the pictures of photoneumeric cellulite severity scale in relation to the number of evident depression, depth of depression, morphological appearance of skin surface alteration, grade of laxity, flaccidity or sagging skin, and the classification scale originally described by Nurnberger and Muller.

- The total scores obtained were recorded and the cellulite severity was determined.

\section{B- Treatment procedures:}

I- Kinesio tape (Tiger $K$ tape): All subject in group (A) were treated by Kinesio-Tape (KT) in form of fan technique application for three days then day off and then another three days each week for six weeks, each time before applying Kinesiotape the area was cleaned using cotton and alcohol.

\section{Tape application/fan technique:}

A- Before applying the kinesiology tape, expose the adhesive side of the tape so that it can be attached to the specific body area. It is natural to want to peel off the backing from the tape; however, this process is not needed as the tape can simply be torn across one of the squares. This treating will not damage the kinesiology tape as only the backing will be removed.

The fan procedure is a type of kinesio tape application used to control swelling of legs. It is commonly used in lymph edema management or for superficial contusions [23]

To make a fan procedure, simply cut an (I) strip, and then make three cuts lengthwise through the tape, leaving about 1-2 inches uncut at one end. This creates four small strips of tape that can then be used to fan out over thigh. By applying the un cut end in the greater trochanter then stretch every strip $75 \%$ of its length then applying it over posterior and medial aspect of the thigh.

When apply Kinesio tape these general rules should be considered.

\section{General rules before application:}

1- Always check for a history of allergies to tape adhesives. 
2- Cleans skin from any oil, cream and massage wax and trim hair if needed.

3- Measure and cut the tape into the size and shape required.

4- Round off the corners at the end of each tape to prevent it from lifting/peeling.

5- Never stretch the ends of the tape and leave between 2 and $3 \mathrm{~cm}$ of tape at each end that remain of un-stretched. Leaving no-stretch at the ends of the kinesio tape was to avoid a shearing type of tension to the skin and will limit any potential for irritation, as the tape is normally kept on for 3 days.

\section{B- After application:}

- On removal, do not rip the tape off as this can irritate the skin.

- It is easier to remove the kinesiology tape if it is moist or even wet.

- Apply a moisturizer to the skin after removal of the tape, as this will help reduce any potential irritation.

II- Intermittent compression therapy: All subjects in group (B) were treated by intermittent compression therapy in form of two sessions per week for six weeks.

Ask female to evacuate her bladder to be relaxed during intermittent compression session. Ask female to assume supine lying position, then the calves of intermittent compression therapy were applied for both lower limb and be sure that calves covered all lower limb from toes to the groin then, ensure that the connection were accurately fixed.

Switch on the intermittent compression device following this parameter pressure $24 \mathrm{mmgh}$ and 20-30 minute for 2 sessions per week for six weeks.

III- Hypo caloric diet: All patients in both groups (A) and (B) were advised to follow the same hypo-caloric diet of $1200 \mathrm{kcal} /$ day for 6 weeks appendix (II).

All females in both groups were instructed to follow these instructions:

- Walk for an hour, 3 times/week.

- Drink 8-10 cups of water a day.

- Avoid tight trousers.

\section{Statistical analysis:}

- Results are expressed as mean \pm standard deviation. Test of normality, Kolmogorov-Smirnov test, was used to measure the distribution of data measured pre-treatment.
- Accordingly, comparison between normally distributed variables in the two groups was performed using unpaired $t$-test. Analysis of covariance (ANCOVA) test,was used to compare the post-treatment values of the two groups on controlling the effect of pre-treatment value. Paired $t$-test was used to compare within group (pre-vs post-treatment) differences.

- In not normally distributed data, comparison between variables in the two groups was performed using Mann Whitney test. While comparison between pre-and post-treatment data in the same group was performed using Wilcoxon Sign Ranks test.

- Statistical Package for Social Sciences (SPSS) computer program (version 19 windows) was used for data analysis. $p$-value $\leq 0.05$ was considered significant.

\section{Results}

Female demographic data:

Table (1): Physical characteristics in the two studied groups.

\begin{tabular}{lllcc}
\hline & $\begin{array}{c}\text { Group A } \\
(\mathrm{n}=15)\end{array}$ & \multicolumn{1}{c}{$\begin{array}{c}\text { Group B } \\
(\mathrm{n}=15)\end{array}$} & $\begin{array}{c}t- \\
\text { value }\end{array}$ & $\begin{array}{c}p \text { - } \\
\text { value }\end{array}$ \\
\hline Age (yrs. $)$ & $22.33 \pm 2.06$ & $22.20 \pm 3.53$ & 0.126 & $0.900(\mathrm{NS})$ \\
Weight $(\mathrm{kg})$. & $75.93 \pm 10.88$ & $74.75 \pm 8.56$ & 0.330 & $0.744(\mathrm{NS})$ \\
Height $(\mathrm{cm}) 2$ & $160.07 \pm 2.89$ & $159.93 \pm 4.30$ & 0.100 & $0.921(\mathrm{NS})$ \\
BMI $(\mathrm{kg} / \mathrm{m})$ & $29.61 \pm 3.92$ & $29.22 \pm 3.23$ & 0.295 & $0.770(\mathrm{NS})$ \\
\hline
\end{tabular}

Data are expressed as mean \pm SD. NS $=p>0.05=$ Not Significant.

\section{Ultrasonography:}

At pre-treatment, there was no statistical significant difference between the mean value of ultrasound in group A $(1.87 \pm 0.38)$ and its corresponding value in group B $(2.02 \pm 0.39)$ with $F$ value $=1.222$ and $p$-value $=0.278$ (Table 2$)$.

On the other hand at post-treatment, there was a statistical significant decrease in the mean value of ultrasound in group B $(1.73 \pm 0.38)$ when compared with its corresponding value in group $\mathrm{A}(1.78$ $\pm 0.37)$ with $\mathrm{F}$-value $=122.252$ and $p$-value $=0.001$ (Table 2).

Table (2): Intra and inter-group comparison between mean values of ultrasound in the two studied groups measured pre-and post-treatment.

\begin{tabular}{lllll}
\hline & $\begin{array}{c}\text { Group A } \\
(\mathrm{n}=15)\end{array}$ & $\begin{array}{c}\text { Group B } \\
(\mathrm{n}=15)\end{array}$ & $\begin{array}{c}\text { F- } \\
\text { value }\end{array}$ & $\begin{array}{c}p \text { - } \\
\text { value }\end{array}$ \\
\hline Pre-treatment & $1.87 \pm 0.38$ & $2.02 \pm 0.39$ & 1.222 & $0.278(\mathrm{NS})$ \\
Post-treatment & $1.78 \pm 0.37$ & $1.73 \pm 0.38$ & 122.252 & $0.001(\mathrm{~S})$ \\
Mean difference & 0.09 & 0.29 & & \\
$\%$ change & $4.81 \downarrow \downarrow$ & $14.36 \downarrow \downarrow$ & & \\
$p$-value & $0.001(\mathrm{~S})$ & $0.001(\mathrm{~S})$ & & \\
\hline
\end{tabular}

Data are expressed as mean $\pm \mathrm{SD}$.

$\mathrm{NS}=p>0.05=$ Not Significant.

$\mathrm{S}=p \leq 0.05=$ Significant 


\section{Round tape measurement:}

At pre-treatment, there was no statistical significant difference between the mean value of round tape measurement in group A $(68.62 \pm 6.61)$ and its corresponding value in group B $(68.47 \pm 7.99)$ with $\mathrm{F}$-value $=0.003$ and $p$-value $=0.956$ (Table 3 ).

On the other hand at post-treatment, there was a statistical significant decrease in the mean value of round tape measurement in group B $(65.98 \pm 7.91)$ when compared with its corresponding value in group A $(66.98 \pm 6.52)$ with $\mathrm{F}$-value $=39.743$ and $p$ value $=0.001$ (Table 3$)$.

Table (3): Intra and inter-group comparison between mean values of round tape measurement in the two studied groups measured pre-and post-treatment.

\begin{tabular}{lllll}
\hline & $\begin{array}{c}\text { Group A } \\
(\mathrm{n}=15)\end{array}$ & \multicolumn{1}{c}{$\begin{array}{c}\text { Group B } \\
(\mathrm{n}=15)\end{array}$} & $\begin{array}{c}\text { F- } \\
\text { value }\end{array}$ & \multicolumn{1}{c}{$\begin{array}{c}p \text { - } \\
\text { value }\end{array}$} \\
\hline Pre-treatment & $68.62 \pm 6.61$ & $68.47 \pm 7.99$ & 0.003 & $0.956(\mathrm{NS})$ \\
Post-treatment & $66.98 \pm 6.52$ & $65.98 \pm 7.91$ & 39.743 & $0.001(\mathrm{~S})$ \\
Mean difference & 1.64 & 2.49 & & \\
$\%$ change & $2.39 \downarrow \downarrow$ & $3.64 \downarrow \downarrow$ & & \\
$p$-value & $0.001(\mathrm{~S})$ & $0.001(\mathrm{~S})$ & & \\
\hline
\end{tabular}

Data are expressed as mean $\pm \mathrm{SD}$.

NS $=p>0.05=$ Not Significant. $\quad \mathrm{S}=p \leq 0.05=$ Significant

\section{Photonumeric cellulite severity scale:}

At pre-treatment, there was no statistical significant difference between the median value of photonumeric cellulite severity scale in group A [12.5 (9.0-14.5)] and its corresponding value in group B [11.5 (7.5-14.5)] with Z-value $=-0.583$ and $p$-value $=0.560($ Table 4$)$.

On the other hand at post-treatment, there was a statistical significant decrease in the median value of photonumeric cellulite severity scale in group B [8.0 (4.50-11.0)] when compared with its corresponding value in group A [9.5 (6.012.0)] with $Z$-value $=-2.124$ and $p$-value $=0.034$ (Table 4).

Table (4): Intra and inter-group comparison between median values of photonumeric cellulite severity scale in the two studied groups measured pre-and posttreatment.

\begin{tabular}{lllrl}
\hline & \multicolumn{1}{c}{$\begin{array}{c}\text { Group A } \\
(\mathrm{n}=15)\end{array}$} & \multicolumn{1}{c}{$\begin{array}{c}\text { Group B } \\
(\mathrm{n}=15)\end{array}$} & $\begin{array}{c}\text { Z\# } \\
\text { value }\end{array}$ & $\begin{array}{c}p \text { - } \\
\text { value }\end{array}$ \\
\hline Pre-treatment & $12.5(9.0-14.5)$ & $11.5(7.5-14.5)$ & -0.583 & $0.560(\mathrm{NS})$ \\
Post-treatment & $9.5(6.0-12.0)$ & $8.0(4.50-11.0)$ & -2.124 & $0.034(\mathrm{~S})$ \\
Mean difference & 3.0 & 3.5 & & \\
Z\#\# value & -3.446 & -3.458 & & \\
$p$-value & $0.001(\mathrm{~S})$ & $0.001(\mathrm{~S})$ & & \\
\hline
\end{tabular}

Data are expressed as median (minimum-maximum).

NS $=p>0.05=$ Not Significant.

$\mathrm{S}=p<0.05=$ Significant.

Z\# = Mann Whitney test.

Z\#\#= Wilcoxon Sign Ranks test.

\section{Discussion}

The purpose of this study was to investigate the effect of kinesio tape versus inter mitten compression therapy on cellulite in females. Thirty females with femoral adipose tissue cellulite grade $\geq 1$ on Nurnberger-Muller scale at their thighs were participated in this study, their ages were ranged from 19 to 25 years and their body mass indices did not exceed $35 \mathrm{~kg} / \mathrm{m}^{2}$. They were selected from students of Faculty of Physical Therapy, Cairo University. Females were randomly divided into two equal groups: Each group was consisting of 15 females. Group (A) (kinesio tape group): This group was received kinesio tape therapy applied 2 times per week for 6 weeks. In addition to low caloric diet $(1200 \mathrm{kcal} /$ day $)$ and condition related advice. Group (B) (intermittent compression therapy group): This group was received intermittent compression therapy 2 times per week for 6 weeks. In addition to low caloric diet (1200kcal/day) and condition related advice as in group (A).

These females were chosen under the following criteria: All subjects were not married female. All females were free from any pathological condition that may affect the results, all females received a good explanation of treatment and measurement devices and all females were conscious and cooperative.

Females who were excluded from the study included the following; liver, respiratory disease, uncontrolled hypertension, malignancy, mental disorder and BMI $>35$.

Measurement were conducted before starting the treatment as a first record, at the end of the sixth week as a second record (final) record. Data obtained from both groups prior and following the treatment program regarding, ultra sound, round tape measurement and photo numeric cellulite severity scale were statistically analyzed and compared.

Concerning group (A), (kinesio tape group) there was a significant reduction in cellulite when measuring subcutaneous tissue thickness by ultra sound (the percent decrease in the mean value of ultra sound were $4.81 \%$ ), by round measurement (the percent decrease in the mean value of round measurement were $2.39 \%$ ) and by cellulite severity scale (there was significant decrease in the median value of cellulite severity scale measured at post treatment [9.5 (6.0-12.0)].

Although it is a widely used technique at present, there is little scientific evidence about its 
possible effects and, moreover, the existing results are controversial. Greater still is the lack of scientific research on the effect of KT in dermatofunctional pathologies, especially with regard to GL [17]

This study is confirmed by Gonzalez [17] who conducted a study to evaluate the use of KT to reduce GL without tension applied and in form of a "web", by directing the banding towards the lymphatic return. The objective of this study is to investigate the effect of KT on GL, comparing morphological and functional aspects of the affected region, before and after treatment with the wrap, using PAFEG as an evaluation method and he found that study bring good results regarding the use of KT to reduce GL and edema.

This study is confirmed with Smykla et al. [24], who stated that K-tape could not replace the compression therapy, and at this moment it must not be an alternative choice for the breast cancerrelated lymphedema patient but it may considered as adjunct supportive treatment.

This study is confirmed by Tomas, [9] who reported significant reduction in cellulite by using kinesio tape therapy, an experienced cosmetologist diagnosed the patient with the first degree of cellulite on the lateral sides of the thighs. After excluding contraindication, an experienced physiotherapist applied the kinesiology taping. The patient was taped at the site of present cellulite. After tape removed the patient was examined again by the same cosmetologist and physiotherapist. The patient and both specialists found a considerable improvement in the skin at the site of tape application. The skin seemed better supplied with blood, more elastic, supple and firm, while cellulite seemed less visible than before the procedure. A great believe that elastic therapeutic tapes may fill the present gap in cellulite reduction was documented.

Cellulite is caused by congestion of fluid in the interstitial space generating an edematous and fibrotic disorder. The kinesio taping is a resource consisting of a bandage, placed on the skin and represent a form of intervention in the treatment of lymph edema and help in the removal of accumulated fluid [25].

Kinesio taping is known to help with oedema reduction and pain relief. Originally used to treat sporting injuries, it is now being used in the treatment of lymphodema to help drain fluid from congested areas. It has since been adopted for use with lipoedema, and can be very useful when there is a fluid component to swelling when compression cannot be tolerated [26]

Clinical evidence is gradually increasing, but community nurses are rarely trained in kinesio taping, thus restricting its use. Tape is usually applied by a therapist and left on 3-4 days, after which time the skin needs washing and moisturizing [26].

Concerning group (B) (intermittent compression therapy group) there was a significant reduction in cellulite when measuring subcutaneous tissue thickness by ultra sound (the percent decrease in the mean value of ultra sound were $14.36 \%$ ), by round measurement (the percent decrease in the mean value of round tape measurement were $3.64 \%$ ) and by cellulite severity scale (there was significant decrease in the median value of cellulite severity scale measured post treatment [8.0 (4.5011.0)].

There were highly statistical significant differences, between the results of group (B) (intermittent compression therapy) and the group (A) (kinesio tape therapy), regarding all measured variables favouring group (B).

This study is confirmed by Eran [28] who reported that the goal of intermittent compression therapy is to decrease symptoms and prevent secondary complication of lipoedema, particularly to reduce pain and decrease the bulk of fat deposition. Conservative treatment should be employed to control associated oedema, and options include: Combined decongestive therapy, manual lymphatic drainage, compression garments or bandages. The effectiveness of compression therapy is minimal, but it is beneficial through the reduction in the interstitial fluid. The better outcome is associated with the introduction of compression therapy to these patients at the early stage of the disease.

This study is confirmed by Sheila et al., 2016, who stated that intermittent compression therapy improves symptom relief and reduces episodes of cellulitis and ulceration in lower-extremity lymphedema, it is well tolerated by patients and should be recommended as an adjunct to standard lymphedema therapy.

Intermittent compression therapy provides a mechanical massage using air-driven pumps and comfortable, inflatable garments that are used over affected areas/swollen limbs. Machines range from one chamber (which squeezes the limbs at a defined pressure) to multi chamber devices that work sequentially. The electric pump is attached to the 
leg/arm garment, which is placed on the patient's limb. Inflation/deflation pressures and times may be pre-set, and the patient experiences a gentle wave of pressure on the limb. Initially thought to cause fibrosis or complicate oedema at the root of the limb, the devices have evolved, with newer models that incorporate a body section so they can replicate a session of MLD with the device following the same pathways [26].

The circumferential compression of the lower extremity by Intermittent Pneumatic Compression (IPC), transmits pressure to the subcutaneous tissues and the muscle groups. Compression increases the interstitial pressure in the extracellular space. When interstitial pressure is greater than the hydrostatic pressure within the vessels, third spaced fluids are forced back into circulation. This phenomenon effectively decreases the cross-sectional area of the lower extremity and decrease the tensile stretch on the cutaneous tissues; especially in patients with an oedematous lower extremity. The decreased surface tension may provide improved transcutaneous oxygenation and clearance of metabolic toxins. (Chen \& Frangos et al., 2001).

Significant differences, between the group (B) intermittent compression therapy and the group (A) kinesio tape therapy, which were in the form of a highly significant decrease in the cellulite grade favouring group (B).

\section{References}

1- ALMEIDA M.C., SERRANO C.S., ROLDAN J.R. and REJANO J.J.: Cellilites aetiology: Areview JEADV, 27: 273-8, 2013.

2- ZEKAYI K., ABDULLAH S., BURHAN E., RASHID $\mathrm{K}$. and OZDEN CALAY: Journal of cosmetic and laser therapy, 2013: Early on line: 1-5, Issn 1476-4172 print/ Issn 1476-4180 on line 2013 in forma UK, Ltd, 2013.

3- ROSSI A. and VERGNANINI A.: Cellulite: A review. J. Eur. Acad Dermatol. Venereol., 14: 251-62, 2000.

4- GOLDMAN M.S.: "Cellulite: A revtew of treatments". J. Cosmet. Dermatol., 15: 17-20, 2002.

5- TAUB A. and SADICK N.: Non Ablative tightening and lifting of the body; in Alam, M. and Dover, J. (eds): Nonsurgical skin tightening and lifging, 1 st ed., Elsevier, Chicago, pp. 120-1, 2008.

6- ORTONNE J.P., ZARTARIAN M., VERSCHOORE M., et al.: Cellulite and skin agmg: Is there any interaction? J. Eur. Acad Dermatol. Venereol., 22 (7): 827-34, 2008.

7- HEXSEL D. and MAZZUCO R.: Subcision. In: Goldman MP, Bacci PA, Leibaschoff G, Hexsel D, Angelini F (eds) Cellulite: Pathophysiology and treatment. Taylor \& Francis, New York, pp. 251-62, 2006.
8- AVRAM M.: Cellulite: A review of its physiology and treatment. J. Cosmet. Laser Ther., 6: 181-5, 2004.

9- TOMAS Z.: Wilk Magdalena Niewglowska-Wilk, Radoslaw Spiewak: Estetol. Med. Kosmetol., 2 (4): 115-7, 2012.

10- CURRI S.B.: Las Microangiopatías. Barcelona: Hausmann, 1989.

11- MEYER P., LISBOA F., ALVES M. and AVELINO M. Desenvolvimento e aplicação de um protocolo de avaliação fisioterapêuticaem pacientes com Fibro edema gelóide. Fisioter. Mov., 18 (1): 75-83, 2005.

12- MILANI G., JOÃO S. and FARAH E.: Fundamentos da fisioterapia dermato-funcional: Revisão de literatura. Fisioterpesqui., 13 (1): 37-43, 2006.

13- GODOY J., BRAILE D. and GODOY M.: Bandagem coadesiva e de baixa elasticidade no tratamento do linfedema. Rev. Angiol. Cirurg. Vasc., 12 (3): 87-9, 2003.

14- CHANDIA P.: Consideraciones generales sobre la técnica de tapinglinfático o vendaje neuromuscular. Linfologia: Tratamiento transdisciplinar, 43 (15): 22-9, 2009.

15- THELEN M., DAUBER J. and STONEMAN P.: The clinical efficacy of kinesio tape for shoulder pain: A randomized, double-Blinded, clinical trial. J. Orthop. Sports Phys. Ther., 38 (7): 389-95, 2008.

16- KASE K., WALLIS J. and KASE T.: Clinical therapeutic applications of the kinesio taping method. 2 nd ed. Kinesio Taping Association, 2003.

17- GONZÁLEZ-IGLESIAS J., FERNANDEZ-De-LASPEÑAS C., CLELAND J., HUIJBREGTS P. and GUTIERREZ-VEGA M.: Short-Term efects of cervical kinesio taping on pain and cervical range of motion in patients with acute whiplash injury: A randomized clinical trial. J. Orthop. Sports Phys. Ther., 39 (7): 515-21, 2009.

18- TSAI H., HUNG H., YANG J., HUANG C. and TSAUO J.: Could Kinesio tape replace the bandage in descongestive lymphatic therapy for breast-cancer-related lymphedema? A pilot study. Support Care Cancer, 17: 207-15, 2009.

19- BIALOSZESWSKI D., WOZNIAK W. and ZAREK S.: Clinical Efficacy of Kinesiology Taping in reducing edema of the lower limbs in patients treated with the Ilizarov Method. Preliminary Report. Ortop, Traumat Reabilit, 11 (1): 50-9, 2009.

20- WAGNER S.: Lymphedema and lipedema-an overview of conservative treatment. Vasa, 40 (4): 271-9, 2011.

21- NURNBERGER F. and IVHILLER G.: So-called cellulite: An invented disease. J. Derma. to I. Surg. Oncol., 4 (3): 221-9, 1978.

22- MLOSEK R., DEBOWSKA R., LEWANDOWSKI M., MALINOWSKA S., NOWICKI A. and ERIS I.: Imaging of the skin and subcutaneous tissue using classical and high frequency ultrasonograghies in anti-cellulite therapy", skin res. Technol., 17 (4): 461-8, 2011.

23- JHON G.: A practical guide to kinesiology taping, 16-28, 2014. 
24- SMYKLA K., WALEWIEZ R., TRYBULSKI T., HALSKI M., KUCHARZEWSKI C., KUCIO W. MIKUSEK K. and TARADAJ J.: Effect of kinesiology taping on breast cancer related lymphedema: A Randomized single-Blind controlled pilot study. Bio. Med. Research International, (767106): 7, 2013.

25- RODRIGO M., RAFAEL L., LUDMILA M., PATRÍCIA F. and PATRÍCIA F.: Effects of Kinesio Taping in treat- ment of Cellulite: Randomized controlled blind trial. $12.175,2014$

26- HARDY D.: Compression Garments, friend or foe? Presentation at Lipoedema UK Conference \& AGM, 26 June, Reading, UK, 2015.

27- ERAN S.: Lipoedema is not lymphoedema: A review of current literature Int. Wound J., 15: 921-8, 2018.

\section{مقابل شريط كينسيس فعالية العلاج بالضغط السيلوليت فتى الإناث}

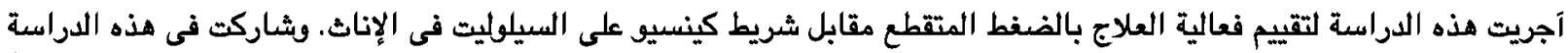

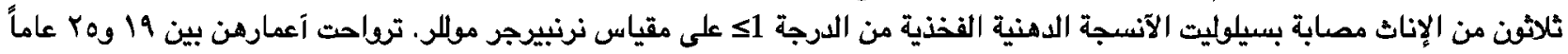

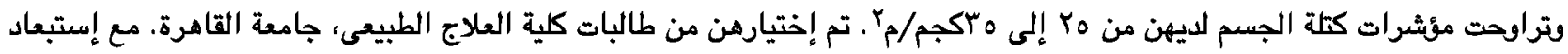

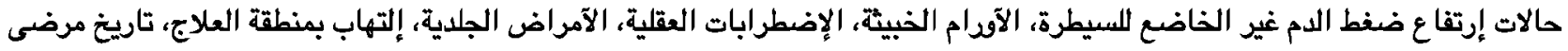
بالخثار الوديدى العميق قد تؤثر على النتائج، وحصلت جميع الإناث على شرح جيد لآجهزة العلاج والقياس وكانت جميع الإناث واعية ومتعاونة.

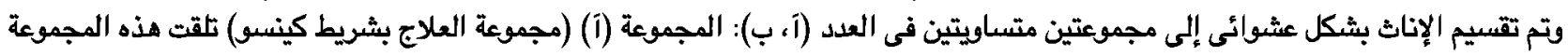

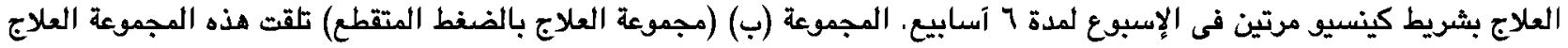
بالضغط المتقطع مرتين فى الإسبوع لمدة 7 آسابيع. 